\title{
PREVALENCE OF MUSCULOSKELETAL COMPLAINTS AMONG DENTISTS IN SOME EGYPTIAN CITIES
} By

\author{
Hegazy A.A* Awadalla N.J** and Shenouda N.S** \\ From \\ *Department of Community and Industrial Medicine, Faculty of Medicine, Al-Azhar University \\ **Department of Community and Occupational Medicine, Faculty of Medicine, \\ Mansoura University.
}

\begin{abstract}
:
Background: Musculoskeletal complaints represent a significant occupational health issue in dentistry. In Egypt, data about the prevalence and risk factors of this problem are little. The aim of the study was to assess the prevalence of musculoskeletal (MSK) complaints among dentists in some Egyptian cities, evaluate the influence of personal characteristics, physical and psychological risk factors at work and health status on the occurrence of MSK complaints and to detect the association between MSK complaints and other contributing factors in the development of sickness absence among dentists. Methods: A self-administered questionnaire was distributed to a random sample of 350 dentists in 3 cities of Egypt (Cairo , Al-mehalla El-kobra and El-mansoura).The questionnaire involved information on the respondent's individual characteristics, job history, physical and psychosocial risk factors at work, general health status, and the occurrence of musculoskeletal complaints.
\end{abstract}

Results: Occupational neck and low-back pain were the most prevalent MSK complaints among dentists in the past 12 months in Egypt (75.1\% and 58.5\%, respectively). On the other hand low-back pain was the most prevalent chronic MSK complaints $(11.4 \%)$ followed by chronic neck pain $(7.4 \%)$. The occurrence of MSK pain was associated with at least one work- related physical load. Especially important was awkward posture followed by improper workplace ergonomics, prolonged static posture, and repetitive movements .High job demands were associated with shoulder and hand/ wrist complaints $(\mathrm{OR}=2.26$ and 2.17 , respectively) . In this study, $27.4 \%$ of the respondents reported sickness absence . Chronic low-back pain was the only complaint that increased the risk of sickness absence $(\mathrm{OR}=4.83)$. BMI $>30$, age $>40$ years, perceived moderate general health, need for recovery and basic education were significant contributing factors for sickness absence.

Conclusions: MSK complaints are a significant occupational health problem among dentists in some Egyptian cities. Interaction of physical load, psychosocial load, general health conditions, and personal criteria in developing the MSK pain require integrated preventive strategies to minimize their impacts.

Key word: Dentists - MSK pain - sickness absence . 


\section{Introduction}

Dentists commonly experience musculoskeletal pain during the course of their career. If regularly occurring pain or discomfort is ignored, the cumulative physiological damage can lead to an injury or a career-ending disability with substantial economic impact from sickness absence, reduced productivity and impact on quality of life ${ }^{1}$.

A number of studies have found that the mechanisms leading to work-related musculoskeletal (MSK) complaints are multifactorial ${ }^{2-5}$. In dentists, pain can be attributed to numerous risk factors including: exposure to physical stressors as overstrained and awkward postures, repetitive movements, frequent standing and sitting and the use of vibrating tools beside psychosocial stressors like high job demand and low job control ${ }^{6}$. In addition to workplace stressors, genetic predisposition, age, and daily life physical stressors may contribute in the development of pain. Body regions most commonly involved are the low- back, neck, shoulders, forearms, and hands ${ }^{7}$.

Musculoskeletal health of dental professionals has been the subject of numerous studies worldwide. In a survey of Danish dentists, 50 per cent and 65 per cent re- ported a one year prevalence of lower back pain and neck/shoulder pain, respectively ${ }^{8}$. A study from Queensland, Australia, found a high prevalence of musculoskeletal problems in dentists, with 87.2 percent reporting at least one musculoskeletal symptom in the previous 12 month ${ }^{9}$. However, in Egypt, data about the prevalence of this problem, body parts distribution and the associated risk factors are little.

\section{The objectives of the study were to:}

1- Assess the prevalence of MSK complaints among dentists in Egypt.

2- Evaluate the influence of personal characteristics, physical and psychological risk factors at work, and health status on the occurrence of MSK complaints.

3- Detect association between MSK complaints and other contributing factors in the development of sickness absence among dentists.

\section{Subjects and methods :}

\section{Study population:}

Three hundred and fifty dental physicians were randomly selected from both University hospital and special clinics in Cairo City , special clinics in Al-mehalla El-kobra City and University hospital in Elmansora City. At least three years of work 
experience in the current position were the only criterion for eligibility to the study. Nearly ninety three percent responded.

\section{Study design and data collection:}

A self-administered questionnaire ${ }^{10}$ was distributed by the researchers between December 2007 and May 2008. The questionnaire involved information on the respondent's individual characteristics, job history, physical and psychosocial risk factors at work, general health status, and the occurrence of musculoskeletal complaints.

Individual characteristics and work history included questions on age, gender, height and weight, body mass index (BMI), marital status, level of education and duration of employment. The BMI was calculated by dividing the weight in $\mathrm{Kg}$ over the square height in meter.

Questions on physical workload concerned repetitive movements, awkward working postures in which the back was bent or twisted, prolonged static postures and strenuous hand and arm positions like working with hands in excessively tight grip or arm elevated or abducted and the use of vibrating tools. Perceived exertion was assessed subjectively at the end of the working day.

Psychosocial aspects at work included job demand and control. Job demand was measured by a group of questions which included working fast and hard, excessive workload, insufficient time to complete duties or conflicting duties. Lack of control was measured by another group of questions related to creativity, task variety, learning new things and amount of repetitive work. In the statistical analysis of demand and control questions, scores above the median were considered as the presence of psychosocial risk.

Perceived general health and need for recovery at the end of work day were assessed subjectively as low, moderate and high.

Musculoskeletal complaints were measured using the standardized Nordic questionnaire ${ }^{10}$. Three end points for each body site were defined (i)Musculoskeletal pain in the past 12 months of back, neck, shoulder or hand/wrist was defined as pain that had continued for at least a few hours during the last 12 months. (ii) Chronic pain in the past 12 months, referred to a complaint that was present almost every day in the preceding 12 months with a minimal duration of at least 1month. (iii) Musculoskeletal pain which led to sickness absence in the past 12 months.

\section{Statistical analysis:}

Data were analyzed using SPSS (Statistical Package for Social Sciences) ver- 
sion 11. Logistic regression analysis was performed to evaluate the influence of individual characteristics, physical and psychosocial risk factors at work, and health status on the occurrence of musculoskeletal complaints. Significant factors predicting MSK complaints on univariate analysis were entered into multivariate logistic regression analysis to find out the independent predictors of MSK complaints. Odds ratio and 95\% confidence interval were calculated. $\mathrm{P} \leq 0.05$ and $\leq 0.001$ were considered statistically significant and highly significant respectively.

\section{Results:}

\section{Response:}

The response rate to participate in the study was $92.9 \%$ (325/ 350 respondents). The reasons for non-participation were lack of time and refusals. Our sample consisted of general dentists (16.3\%) and specialists $(83.7 \%)$.

\section{Individuals characteristics:}

Table 1 shows the individual and job characteristics of the study group. The study group consisted mostly of males (57.8\%) with ages ranging from 27 to 58 years, while $42.1 \%$ were females with ages ranging from 27 to 56 years. Working long hours per week was related to male gender (49.45 \pm 15.7 hours/week compared to 34.39 \pm 8.6 hours/week in females $\mathrm{P}<0.001)$ and post graduate degree $(43.41 \pm 15.9$ working hours/week compared to $41.53 \pm 9.9$ in university degree).

\section{Prevalence of MSK complaints:}

The prevalence of musculoskeletal complaints among dentists is presented in table 2. Neck pain was the most prevalent musculoskeletal complaints in the past 12 months as well as in the past week (75.1\% and $67.7 \%$, respectively), followed by lowback pain ( $58.5 \%$ and $56.0 \%$, respectively) , while hand / wrist pain was the least prevalent ( $47.4 \%$ and $39.1 \%$, respectively). On the other hand low-back pain was the most prevalent chronic MSK complaints (11.4\%) followed by chronic neck pain ( $7.4 \%$ ) and resulted in a significantly higher chronicity than any other complaint. Chronic shoulder and hand / wrist complaints were less prevalent than low-back pain.

Association between risk factors and MSK complaints:

Table 3 presents the univariate analysis for the potential risk factors of neck and shoulder pain in the past 12 months. All risk factors were dichotomized before they were entered into logistic regression. At least one physical risk factor was significantly related to the occurrence of neck and shoulder pain. However repetitive 
movements, improper workplace ergonomics and prolonged static posture were significant risk factors for occurrence of neck pain complaint with $\mathrm{OR}=1.81,2.1$ and 2.61, respectively, while awkward back posture was the only significant factor for shoulder pain.

Psychosocial risk factors (high job demand and low job control) were not associated with the occurrence of neck pain complaints in the past 12 months, while high job demand was a significant risk factor for shoulder pain complaint ( $\mathrm{OR}=2.01$ ). Also, high need for recovery at the end of the work day and high perceived exertion were significantly associated with shoulder pain (OR=2.40 and 2.26, respectively) and with neck pain $(\mathrm{OR}=2.40$ and 1.75 , respectively). Additionally moderate health status was a significant risk factor associated with the occurrence of shoulder complaints in the past 12 months $(\mathrm{OR}=3.63)$.

On the other hand, none of the personal factors were significantly contributing to the development of neck or shoulder pain.

Table 4 shows univariate analysis for the risk factors of hand /wrist and low-back pain in the past 12 months. Most of the physical factors [work with vibrating tools, repetitive movements, awkward back posture and prolonged static posture $(\mathrm{OR}=$
, 2.78, 2.44, 3.66 and 4.5, respectively )] were significant physical risk factors for the occurrence of low-back pain. While , awkward back posture and improper workplace ergonomics $(\mathrm{OR}=2.35$ and 2.22 , respectively ) were the only significant physical risk factors in the development of hand/ wrist pain . Psychosocial risk factors ( high job demand and low job control) were not associated with the occurrence of low-back pain but high job demand $(\mathrm{OR}=2.37)$ was significant psychosocial risk factor in the occurrence of hand /wrist pain.

High need for recovery at the end of the work day was a significant risk factor in the development of low-back pain and hand / wrist pain (odds ratio 1.65 and 1.78, respectively). While, high perceived exertion was a significant risk factor $(\mathrm{OR}=1.74)$ for the development of hand /wrist pain only.

Regarding the personal characteristics, it was observed that female gender was a highly significant factor and single status, shift work and body mass index more than 30 were significant factors for the development of low-back pain $(\mathrm{OR}=2.48,2.22,2.46$ and 2.8 , respectively). On the other hand, Age $>40$ years, Female gender and post graduate degree significantly decreased the risk of hand /wrist pain (odds ratio 0.24, $0.54,0.4$, respectively) while family situation (being single status and care of children <5years 
old were related to increased risk of hand / wrist pain ( $\mathrm{OR}=1.96$ and 2.89, respectively). In female dentists; care of children below the age of five years was found to increase the risk of MSK complaints in the different bodily regions and in particularly the lowback $(\mathrm{OR}=5.23)$.

The results of multivariate analysis for the risk factors of neck and shoulder pain in the past 12 months are shown in table 5 . Significant independent predictors of neck pain were, in decreasing order; repetitive movements $(\mathrm{OR}=2.51)$, need for recovery at the end of the work day $(\mathrm{OR}=2.25)$, prolonged static posture $(\mathrm{OR}=2.11)$ and high perceived exertion $(\mathrm{OR}=1.86)$. On the other hand, the significant independent predictors of shoulder pain were, in decreasing order; strenuous back posture $(\mathrm{OR}=4.78)$, moderate general health $(\mathrm{OR}=4.07)$ and high job demand $(\mathrm{OR}=2.26)$.

Multivariate analysis for the risk factors of hand/wrist and low-back pain in the past 12 months was presented in table 6. Significant independent predictors of low back pain were, in decreasing order; work with vibrating tools $(\mathrm{OR}=4.33)$, prolonged static posture $(\mathrm{OR}=4.31)$, repetitive movements $(\mathrm{OR}=3.36)$, being single status $(\mathrm{OR}=2.50)$ and female gender $(\mathrm{OR}=2.22)$. On the other hand, the significant independent predictors of hand/wrist pain were, in decreasing order; care of children $<5$ years old $(\mathrm{OR}=2.20)$, high job demand $(\mathrm{OR}=2.17)$ and need for recovery at the end of the work day $(\mathrm{OR}=1.64)$.

\section{MSK complaints and sickness absence}

About twenty seven percent (27.4\%) of the studied dental physicians suffered from one or more sickness absence episodes because of MSK complaints. Chronic low-back pain was the only significant MSK complaint which increased the risk of sickness absence $(\mathrm{OR}=4.83)$. The other significant contributing factors for sickness absence, other than complaints, were in decreasing order; perceived moderate general health, BMI $>30$, age $>40$ years old, university degree and need for recovery at the end of the work day $(\mathrm{OR}=4.08,4.02,3.06$, 2.90 and 2.62, respectively) (table 7). 
Table (1): Individual and job characteristics among dentists $(n=325)$

\begin{tabular}{|l|c|}
\hline \multicolumn{1}{|c|}{ Characteristics } & Dentists \\
No $(\%)$
\end{tabular}

Table (2): Prevalence of musculoskeletal complaints among dentists $(n=325)$.

\begin{tabular}{|l|c|c|c|c|}
\hline \multicolumn{1}{|c|}{ Characteristics } & $\begin{array}{c}\text { Neck } \\
\text { pain } \\
\mathbf{n}(\%)\end{array}$ & $\begin{array}{c}\text { Shoulder } \\
\text { pain } \\
\mathbf{n}(\%)\end{array}$ & $\begin{array}{c}\text { Hand/ } \\
\text { wrist pain } \\
\mathbf{n}(\%)\end{array}$ & $\begin{array}{c}\text { Low- back } \\
\text { pain } \\
\mathbf{n}(\%)\end{array}$ \\
\hline - Occurrence in the past week & $220(67.7)$ & $180(55.4)$ & $127(39.1)$ & $182(56.0)$ \\
- Occurrence in the past 12 months & $244(75.1)$ & $177(54.5)$ & $154(47.4)$ & $190(58.5)$ \\
- Chronic complaints(>1month) & $24(7.4)$ & $14(4.3)$ & $10(3.1)$ & $37(11.4)$ \\
\hline
\end{tabular}


Table (3): Univariate analysis for the risk factors of neck and shoulder pain in the last 12 months.

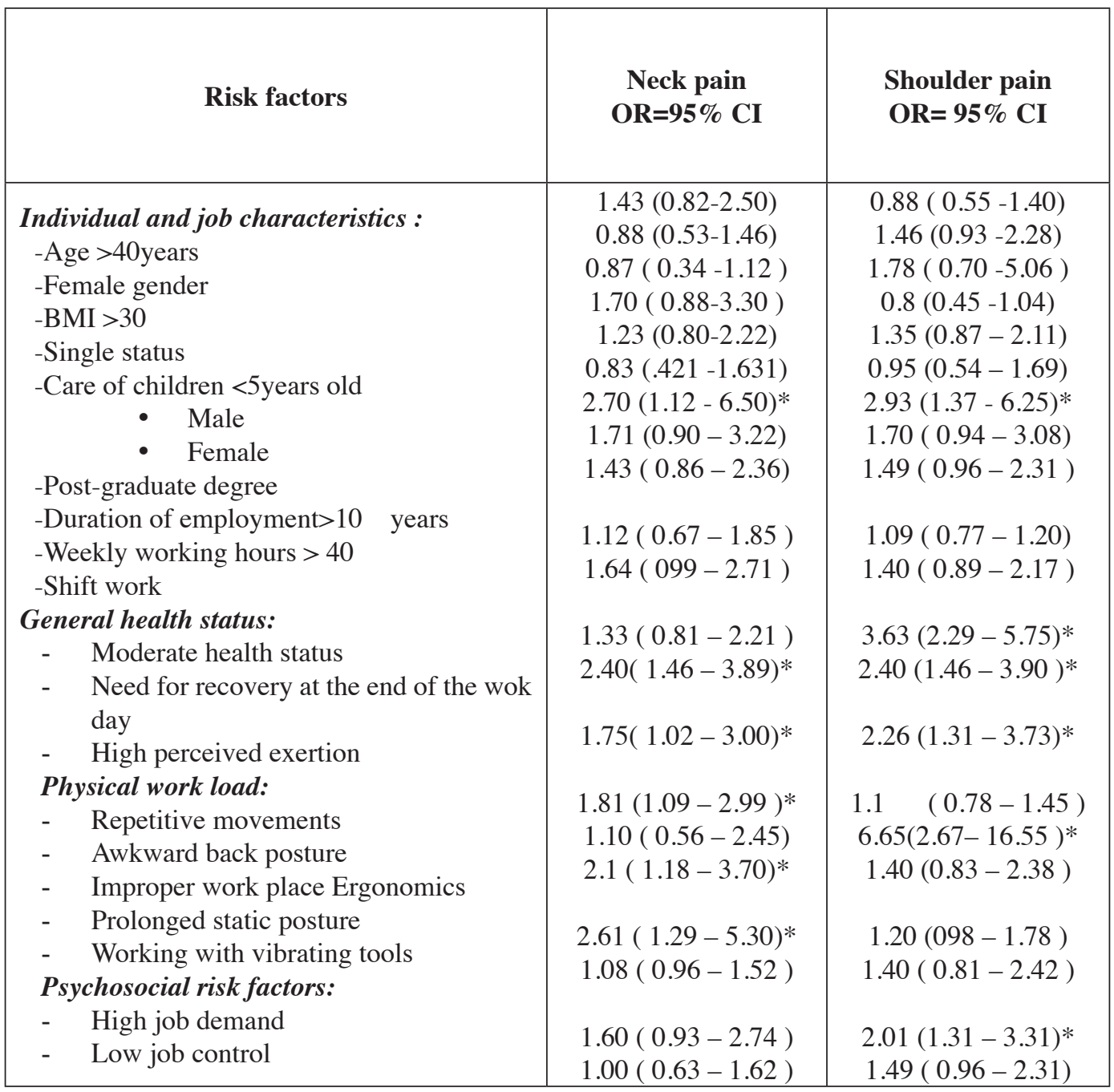

$* \chi^{2}$ test, $\mathrm{p}<0.05 . * * \mathrm{p}<0.001 . \mathrm{OR}=$ Odds ratio; $95 \% \mathrm{CI}=95 \%$ confidence interval 
Table (4): Univariate analysis for the risk factors of hand/ wrist and low- back pain in the last 12 months.

\begin{tabular}{|c|c|c|}
\hline Risk factors & $\begin{array}{c}\text { Hand / wrist pain } \\
\text { OR=95\% CI }\end{array}$ & $\begin{array}{c}\text { Low-back pain } \\
\text { OR=95\% CI }\end{array}$ \\
\hline \multicolumn{3}{|l|}{ Individual and job characteristics: } \\
\hline -Age $>40$ years & $0.24(0.14-0.40)^{* *}$ & $1.29(0.80-2.08)$ \\
\hline -Female gender & $0.54(.34-0.85)^{*}$ & $2.48(1.55-3.95)^{* *}$ \\
\hline$-\mathrm{BMI}>30$ & $1.25(0.49-3.16)$ & $2.8(1.00-8.60)^{*}$ \\
\hline -Single status & $1.96(1.15-3.33)^{*}$ & $2.22(1.23-3.94)^{*}$ \\
\hline -Care of children $<5$ years old & $2.89(1.84-4.55)^{* *}$ & $1.21(0.90-2.20)$ \\
\hline$\bullet \quad$ Male & $2.67(1.47-4.82)^{*}$ & $0.46(0.25-0.82)$ \\
\hline$\bullet \quad$ Female & $2.80(1.36-5.73)^{*}$ & $5.23(2.48-11.05)^{* *}$ \\
\hline -Post-graduate degree & $0.4(0.21-0.74)^{*}$ & $1.01(0.55-1.80)$ \\
\hline -Duration of employment $>10 \quad$ years & $1.00(0.56-1.31)$ & $1.00(0.55-1.45)$ \\
\hline -Weekly working hours $>40$ & $1.05(0.68-1.64)$ & $1.05(0.67-1.64)$ \\
\hline -Shift work & $1.02(0.57-1.21)$ & $2.46(1.54-3.90)^{*}$ \\
\hline \multicolumn{3}{|l|}{ General health status: } \\
\hline - $\quad$ Moderate health status & $1.20(0.73-1.11)$ & $1.48(0.95-2.31)$ \\
\hline - $\quad$ Need for recovery at the end of the wok day & $1.78(1.12-2.86)^{*}$ & $1.65(1.03-2.64)^{*}$ \\
\hline - $\quad$ High perceived exertion & $1.74(1.05-2.87)^{*}$ & $1.02(0.56-1.91)$ \\
\hline \multicolumn{3}{|l|}{ Physical work load: } \\
\hline - $\quad$ Repetitive movements & $1.42(0.91-2.21)$ & $2.44(1.55-3.85)^{*}$ \\
\hline - $\quad$ Awkward back posture & $2.35(1.08-5.10)^{*}$ & $3.66(1.47-9.11)^{*}$ \\
\hline - Improper work place Ergonomics & $2.22(1.28-3.87)^{*}$ & $1.04(0.61-1.77)$ \\
\hline - $\quad$ Prolonged static posture & $1.02(0.65-1.81)$ & $4.5(2.1-9.66)^{* *}$ \\
\hline - $\quad$ Working with vibrating tools & $1.58(0.90-2.70)$ & $2.78(1.58-4.86)^{*}$ \\
\hline \multicolumn{3}{|l|}{ Psychosocial risk factors: } \\
\hline - $\quad$ High job demand & $2.37(1.50-3.75)^{*}$ & $1.16(0.73-1.83)$ \\
\hline - $\quad$ Low job control & $1.03(0.56-1.47)$ & $1.02(0.55-1.45)$ \\
\hline
\end{tabular}

$* \chi^{2}$ test, $\mathrm{p}<0.05 . * * \mathrm{p}<0.001 . \mathrm{OR}=$ Odds ratio; $95 \% \mathrm{CI}=95 \%$ confidence interval 
Table (5): Multivariate analysis for the risk factors of Neck and Shoulder pain in the last 12 months.

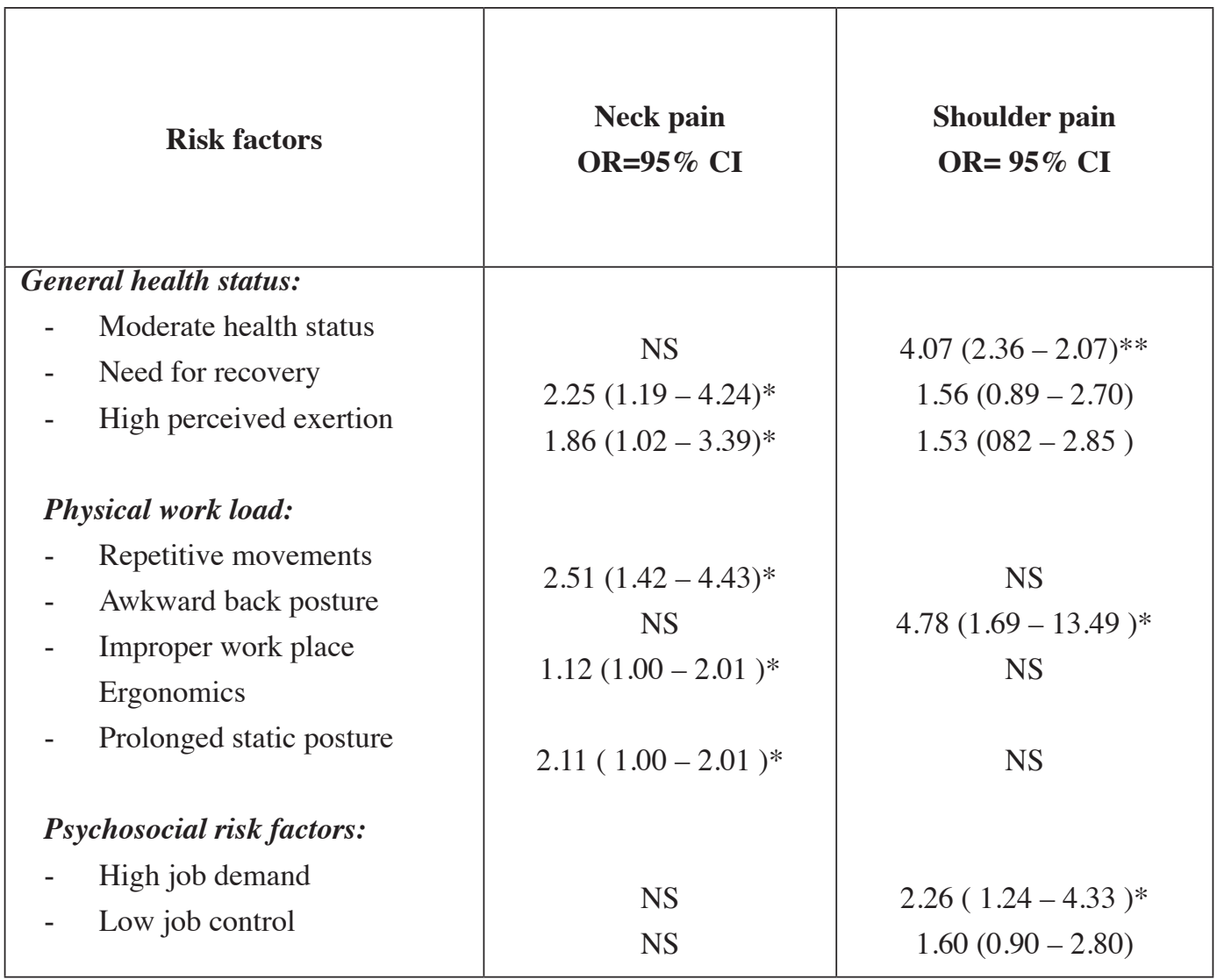

$* \chi^{2}$ test, $\mathrm{p}<0.05 . * * \mathrm{p}<0.001 . \mathrm{OR}=$ Odds ratio; $95 \% \mathrm{CI}=95 \%$ confidence interval, $\mathrm{NS}=$ not studied. 
Table (6): Multivariate analysis for the risk factors of shoulder and low- back pain in the last 12 months.

\begin{tabular}{|c|c|c|}
\hline Risk factors & $\begin{array}{c}\text { Shoulder } \\
\text { OR=95\% CI }\end{array}$ & $\begin{array}{c}\text { Low-back pain } \\
\text { OR=95\% CI }\end{array}$ \\
\hline \multicolumn{3}{|l|}{ Individual and job characteristics: } \\
\hline -Age $>40$ years & $0.48(0.23-1.00)^{*}$ & NS \\
\hline -Female gender & $0.53(0.31-0.89)^{*}$ & $2.22(1.27-3.87)^{*}$ \\
\hline -Single status & $1.31(0.62-2.68)$ & $2.5(1.12-5.20)^{*}$ \\
\hline -Care of children $<5$ years old & $2.20(1.22-3.98)^{*}$ & NS \\
\hline -Post-graduate degree & $0.61(0.30-1.22)$ & NS \\
\hline -Duration of employment $>10$ years & $0.62(0.33-1.16)$ & $0.76(0.42-1.39)$ \\
\hline -Shift work & NS & $1.28(0.61-2.59)$ \\
\hline \multicolumn{3}{|l|}{ General health status: } \\
\hline $\begin{array}{l}\text { - Need for recovery at the end of the } \\
\text { work day }\end{array}$ & $1.64(0.94-2.87)^{*}$ & NS \\
\hline - $\quad$ High perceived exertion & $1.02(0.87-1.9)$ & NS \\
\hline \multicolumn{3}{|l|}{ Physical work load: } \\
\hline - $\quad$ Repetitive movements & NS & $3.36(1.95-5.81)^{* *}$ \\
\hline - $\quad$ Awkward back posture & $1.33(0.54-3.25)$ & $1.16(0.50-2.68)$ \\
\hline - $\quad$ Improper work place Ergonomics & $1.14(0.67-1.94)$ & $1.33(0.75-2.35)$ \\
\hline - $\quad$ Prolonged static posture & NS & $4.31(1.79-10.36)^{* *}$ \\
\hline - $\quad$ Working with vibrating tools & NS & $4.33(2.12-8.88)^{* *}$ \\
\hline Psychosocial risk factors: & & \\
\hline - $\quad$ High job demand & $2.17(1.20-3.92)^{*}$ & NS \\
\hline
\end{tabular}

$* \chi^{2}$ test, $\mathrm{p}<0.05 . * * \mathrm{p}<0.001 . \mathrm{OR}=$ Odds ratio; $95 \% \mathrm{CI}=95 \%$ confidence interval, $\mathrm{NS}=$ not studied. 
Table (7): Sickness absence from musculoskeletal complaints and other contributing factors in the last 12 months among dentists $(n=325)$.

\begin{tabular}{|l|c|}
\hline \multicolumn{1}{|c|}{ Risk factors } & OR ( 95\% CI) \\
\hline Prevalence in the last 12 months & $27.4 \%$ \\
Site of chronic pain: & \\
- Neck & \\
- Shoulder & $0.51(0.16-1.53)$ \\
- Hand / wrist & $2.06(0.69-6.15)$ \\
- Low-back & $0.30(0.13-2.30)$ \\
& $4.83(2.38-2.30) * *$ \\
Significant contributing factors: & \\
- Age > 40 years & \\
- BMI > 30 & $3.06(1.85-5.10)^{* *}$ \\
- Moderate health status & $4.02(1.56-10.35)^{*}$ \\
- Need for recovery at the end of work day & $4.08(2.31-7.20)^{*}$ \\
- Post-graduate degree & $2.62(1.58-4.35)^{*}$ \\
& $2.90(1.58-5.33)^{*}$ \\
\hline
\end{tabular}

$* \chi^{2}$ test, $\mathrm{p}<0.05 . * * \mathrm{p}<0.001 . \mathrm{OR}=$ Odds ratio; $95 \% \mathrm{CI}=95 \%$ confidence interval. 


\section{Discussion}

The high response rate( $92.9 \%)$ of dental physicians from 3 big Egyptian cities besides the considerable number of participants may strengthen the study and reflect the true prevalence and the associated risk factors of MSK pain among the dental professionals in Egypt.

\section{Prevalence of MSK complaints}

Among dentists in the 3 Egyptian cities occupational neck and low back pain were the most prevalent MSK complaints in the 12 months previous to the study $(75.1 \%$ and $58.5 \%$, respectively). These prevalences are more or less similar to those found by Finsen et al. ( $65 \%$ and 59\%, respectively) 8 and by a study in Saudi Arabia (65\% and $73.5 \%$, respectively) ${ }^{11}$ but much higher than the prevalences reported by other studies $(37 \%$ to $60 \%)$. $^{2,9,12,13}$. The study also, revealed that the 12-month period prevalence of shoulder pain $(54.5 \%)$ was as prevalent among United States military dentists $(53 \%)^{14}$ and Australian dentists (53.3\%) ${ }^{9}$. In addition, (47.4\%) of the dentists reported hand/wrist pain which was more than that reported in the Australian study $(31 \%)^{9}$ and less than that reported by United Stated military study $(75 \%){ }^{14}$. On the other hand low back pain was the most prevalent chronic MSK pain (11.4\%) followed by chronic neck pain $(7.4 \%)$. These results are nearly similar to those reported by Alexopoulos et al.(2004) $)^{15}(12 \%$ and $10 \%$, respectively).

Milerad and Ekenvall ${ }^{16}$ studied the symptoms of the neck, shoulder, arms and hands in a comparative study of 99 dentists and 100 pharmacists and found a higher prevalence of MSK symptoms in dentists compared to pharmacists. The authors concluded that these higher frequencies among dentists were probably connected with their difficult positions, cervical flexion and rotation, and repetitive precision-demanding hand grips.

\section{Risk factors of MSK complaints}

Analysis of the association of risk factors and MSK pain revealed the interaction of physical load, psychosocial load, general health conditions, and personal characteristics in developing the MSK pain, which was in accordance with several other studies ${ }^{2,15}$.

The occurrence of MSK pain of the low- back, neck, hand/ wrist and shoulder among dentists was associated with at least one work-related physical load. Especially important was awkward posture (significant for low- back, hand/ wrist and shoulder pain ) followed by improper workplace ergonomics, prolonged static posture, and repetitive movements (low- back and neck pain). 
Awkward postures in dentists often consist of forward bending and repeated rotation of the head, neck and trunk to one side ${ }^{17}$. Overtime, the muscles responsible for rotating the body to one side can become stronger and shorter, while the opposing muscles become weaker and elongated. The stressed shortened muscles can become ischemic and painful, exerting asymmetrical forces on the spine that can cause misalignment of the spinal column and decreased range of motion in one direction compared to the other. This imbalance between muscles that stabilize and those that move occur in different situations in dentistry. Similarly, awkward arm posture develops muscle imbalance which in turn puts the muscles into strain. This stress can result in ischemia and pain in the overworked muscles. Within the vertebral disks, increased pressure leads to degenerative changes putting the disk at risk of injury ${ }^{1}$.

Dentists frequently assume prolonged static postures (PSPs), which require that 50 per cent of the body's muscles contract to hold the body motionless while resisting gravity $^{12}$. When the human body is subjected repeatedly to PSPs, it can initiate a series of events which include; muscle imbalances, ischemia, pain, joint hypomobility and spinal disk degeneration ${ }^{1}$.
In dentists, bad workplace ergonomics and dentist' chair design result in reduced access and visibility which force the dentists to take awkward postures and repetitive movements that increase the muscle strain and in turn the development of MSK pain ${ }^{18}$.

In the present study, the effect of psychosocial factors in the development of MSK pain was inconsistent. A high job demand was significantly associated with the development of shoulder pain and hand/ wrist pain. Additionally, high need for recovery at the end of the work day and high perceived exertion were significantly associated with shoulder pain, neck pain and hand/wrist pain. Also, moderate health status was a significant risk factor associated with the occurrence of shoulder complaints in the past 12 months. High job demand increases the need for recovery, which is related to worse perceived health. This might reflect an influence particularly on more severe disease or an effect on people's ability to cope when symptoms occurred ${ }^{15}$ . Lehto et al., ${ }^{13}$ found a higher prevalence of MSK pain among dentists with high perceived job demand. High job demand increases the muscle strain and decreases the ability to cope with the symptoms ${ }^{19}$.

Significant relations were found between self-reported personal factors and 
the occurrence of MSK complaints. The experienced dentists (age $>40$ years old and highly educated) were less prone to develop MSK complaints and in particular the hand/ wrist pain. The possible explanations were that experienced dentists are probably better at adjusting their working positions and techniques in order to avoid musculoskeletal problems compared to their less experienced counterparts, or simply that those dentists developed coping strategies to deal with the pain ${ }^{9}$.

Risk of MSK pains and particularly the hand/wrist pain $(\mathrm{P}<0.005)$ with the exception of low- back pain were noted to be higher among males compared to females. This could be related to the high work load in male dentists compared with females (49.45 15.7 working hours/week compared to $34.39 \pm 8.6$ in females $\mathrm{P}<0.001$ ). On the other hand, female gender was significantly related to back pain; several studies reported that women were more likely to experience repeated episodes of back pain than men in similar occupations ${ }^{20,21}$.

In female dentists; caring of children below the age of five years was found to increase the risk of MSK complaints in the different bodily regions. Women with children have been reported to develop more neck and shoulder problems than women with no children due to an increase in home strains ${ }^{24,25,26}$. An increase in the number of dependants may lead to a decrease in women's leisure time and an increase in responsibilities and stress level, which could be manifest in increased prevalence of MSK pain ${ }^{27}$.

\section{MSK complaints and sickness absence}

About twenty seven percent $(27.4 \%)$ of the studied dental physicians suffered from one or more sickness absence episodes because of MSK complaints. This figure is approximately similar to that reported by Alexopoulos et al., ${ }^{15}$ (24\%) and reflects a high economic and social burden of MSK problems in Egyptian dentists. Chronic low-back pain was the only significant MSK complaint that increased the risk of sickness absence $\quad(\mathrm{OR}=4.83)$. Several studies reported that sickness absence was much more frequent in the case of back pain than in any other body sites 22,15 .

Perceived moderate general health, need for recovery at the end of the work day and post graduate degree were found to increase the risk of sickness absence from MSK pain. This may reflect the value of these factors in affecting strategies for coping with MSK complaints ${ }^{15}$.

In the present study the risk of MSK pain-related sickness absence increased with $\mathrm{BMI}>30$ and age $>40$ years old. Obe- 
sity increases the burden and severity of several diseases including osteoarthritis ${ }^{23}$. Also, it was found that sickness absence duration and frequency for a MSK pain episode increased with age and this may reflect the cumulative effects and the associated degenerative changes ${ }^{21,1}$.

\section{Conclusions:}

MSK complaints are significant occupational health problems among dental professionals in Egypt. Their medical, social, and economic consequences justify extensive preventive efforts. Interaction of physical load, psychosocial load, general health conditions, and personal characteristics in developing the MSK pain require integrated preventive strategies and most likely have to take into account workplace ergonomic improvements, knowledge and skill improvement regarding ergonomics and safe work practice, organization of dental work in order to minimize job demand, encouragement of physical exercise as it increases the sense of wellbeing and strengthens the locomotor system.

\section{Study limitations}

-The findings of this study are based on self-reported information provided by dentists and some potential for reporting bias may have occurred because of respondents' interpretation of the questions or desire to report their emotions in a certain way or simply because of inaccuracies of responses.

\section{References}

1. Valachi B. and Valachi K. (2003): Mechanisms leading to musculoskeletal disorders in dentistry. JADA; 134: 1344-50 .

2. Westgaard RH. (1999): Effects of physical and mental stressors on muscle pain. Scand J work Environ health; 25(4):19-24

3. Karwowski W and Marras WS (1999): The Occupational ergonomics hand book. Boca Raton, Fla.: CRC Press;169-70.

4. Cailliet R. (1996): Soft tissue pain and disability. 3rd ed. Philadelphia: F.A. Davis. 1-12.

5. Szymanska J. ( 2002) : Disorders of the musculoskeletal system among dentists from the aspect of ergonomics and prophylaxis. Ann Agric Environ Med ; 9: 169-173.

6. Buckle P. ( 2005) : Ergonomics and musculoskeletal disorders : overview: Occup Med; 55: 16467.

7. Punnett L. and Wegman D.H.( 2004): Workrelated musculoskeletal disorders: the epidemiologic evidence and the debate. J. Electromyogra Kinesiology; 14: 13-23.

8. Finsen L, Christensen H and Bakke M. (1998): Musculoskeletal disorders among dentists and variation in dental work. Appl Ergon; 29: 11925 .

9. Leggat P.A. and Smith D.R. ( 2006 ) : Musculoskeletal disorders self- reported by dentists in Queensland, Australia. Austr Dent J ; 51: (4) : 324-7. 
10. Kuorinka L, Jonsson B, Kilbom A, Vinterberg H, Biering-Sorensen F, Andersson G,and Jorgensen K (1987): Standardized Nordic questionnaires for the analysis of musculoskeletal symptoms. Appl Ergonm; 18:233-7

11. Al Wazzan KA, Almas K, Al Sheethri SE and Al-Qahtani MQ (2001): Back and neck problems among dentists and dental auxiliaries. J Contemp Dent Pract; 2:17-30.

12. Ratzon NZ, Yaros T, Mizlik A , and Kanner $\mathrm{T}$ (2000): Musculoskeletal symptoms among dentists in relation to work posture. Work; 15 : 153-8.

13. Lehto TU, Helenius HY,and Alaranta HT. Musculoskeletal symptoms of dentists assessed by a multidisciplinary approach (1991). Comm Dent Oral Epidemiol; 19:38 - 44.

14. Rice VJ, Nindl B and Pentikis JS (1996): Dental workers, musculoskeletal cumulative trauma, and carpal tunnel syndrome, who is at risk? A pilot study. Int J Occup Saf Ergon; 2: 218-233.

15. Alexopoulos EC, Stathi IC and Charizani F (2004): Prevalence of musculoskeletal disorders in dentists. www.biomedcentral.com/1471-2474 /5/16.

16. Milerad E and Ekenvall L (1990): Symptoms of the neck and upper extremities in dentists. Scand J Work Environ Health; 16: 129-34.

17. Rundcrantz BL, Johnsson B and Moritz U (1991): Occupational cervicobronchial disorders among dentists: analysis of ergonomics and locomotor functions. Swed Dent J; 15:105-15.

18. Pollack R (1996): Dental office ergonomics: how to reduce stress factors and increase efficiency. $\mathrm{J}$ Can Dent Assoc; 62: 508-10.
19. Skov T, Borg V,and Orhede E.(1996): Psychosocial and physical risk factors for musculoskeletal disorders of the neck, shoulders, and lower back in salespeople. Occup Environ Med ;53: 351-6.

20. Lotter F., and Burdof A.(2006): Prognostic factors for duration of sickness absence due to musculoskeletal disorders. Clin J Pain. ;22: 212-21.

21. Oleske DM, Lavender SA, Andersson GB, et al. (2006): Risk factors for recurrent episodes of work-related low back disorders in an industrial population. Spine. ;31: 789-98.

22. Lalumandier JA, McPhee SD, Parrott CB, and Vendemia M,(2001): Musculoskeletal pain: prevalence, prevention, and differences among dental office personnel. Gen Dent ; 49(2):160-6.

23. Must A, Spadano J, Coakley EH, et al.( 1999): The disease burden associated with overweight and obesity. JAMA. ;282: 1523 - 9.

24. Habib RR, Hamdan M, Nuwayhid I, and Odaymat F (2005): Musculoskeletal Disorders Among Full-Time Homemakers in Poor Communities. Wom Health. ; 42(2): 1-14.

25. Björkstén MG, Boquist B, Talbäck M and Edling C (2001): Reported neck and shoulder problems in female industrial workers: The importance of factors at work and at home. Int $\mathbf{J}$ Ind Ergo ; 27(3):159-70.

26. Yun MH, Yun GL, Hong JE and Sang HL(2001): Results of a survey on the awareness and severity assessment of upper-limb work-related musculoskeletal disorders among female bank tellers in Korea. Int J Ind Ergo ; 27(5):347-57.

27. Fredriksson K, Alfredsson L, Köster M, Thorbjörnsson $\mathrm{CB}$, Toomingas $\mathrm{A}$, Torgén $\mathrm{M}$ and Kilbom $\AA$ (1999): Risk factors for neck and upper limb disorders: Results from 24 years of follow up. Occup and Env Med;56(1):59-67. 